\title{
Is the Glycaemic control in Type 1 Diabetes Mellitus affected by Vitamin D status?
}

Donatella Pintus', Dinesh Giri', Supriya Phanse', Fulya Mehta1, Princy Paul', Senthil Senniappan¹

1DEPARTMENT OF PAEDIATRIC ENDOCRINOLOGY AND DIABETES, ALDER HEY CHILDREN'S HOSPITAL, LIVERPOOL, UK

\section{Background}

Evidence from animal studies show that there is a relationship between plasma Vitamin D concentration and glucose homeostasis. Studies have also examined the relationship between Vitamin D status and Type 2 Diabetes Mellitus in adult population. There is paucity of evidence examining the relationship between the glycaemic control in children and adolescents with Type I diabetes Mellitus ( T1DM) and Vitamin D status.

\section{Objective}

To evaluate the relationship between glycaemic status (HbA1C and plasma $25(\mathrm{OH})$ Vitamin D levels in children and adolescents with Type I Diabetes Mellitus.

\section{Methods}

Retrospective data was collected from 348 children and adolescents with T1DM. The serum 25(OH) Vitamin D concentrations were measured at diagnosis and as part of the annual assessment. Patients were categorized as: Vitamin D deficient (<25nmol/L), insufficient $(25-50 \mathrm{nmol} / \mathrm{L})$ or sufficient (>50nmol/L). Vitamin D deficiency was treated with 6000 units of cholecalciferol once a day or 20000 units once a week for 6-8 weeks. All patients had their HbA1C measured every 3 months. Plasma $25(\mathrm{OH}) \mathrm{Vitamin} D$ was measured after the completion of treatment.

\section{Results}

The mean $25(\mathrm{OH})$ Vitamin D concentration was $54 \mathrm{nmol} / \mathrm{L}$ ( \pm 22.9 ). 52.4\% of patients had normal Vitamin D concentrations ( $94 \%$ white ethnicity, $2 \%$ somali), $39.1 \%$ were vitamin $\mathrm{D}$ insufficient (87\% white ethnicity, $4 \%$ somali) and $8.4 \%$ were vitamin D deficient (79\% white ethnicity, 7\% Arabic, 7\% mixed background)(Table1). The mean $\mathrm{HbA1C}(\mathrm{mmol} / \mathrm{mol})$ for the groups with adequate, insufficient and deficient Vitamin D concentration(nmol/ll) were $72.36,72.18$ and 69.41 respectively. The mean $\mathrm{HbA} 1 \mathrm{C}$ ( mmol/mol) prior to treatment with vitamin D supplements was $70.85( \pm 18.9)$ and post treatment was $69.85( \pm 15.95)[p=0.64]$.(Table 2$)$. There was no significant correlation between Vitamin D concentration and $\mathrm{HbA} 1 \mathrm{C}(r=0.05, \mathrm{p}=0.2)$

Table 1:HbA1c amongst Vitamin D deficient, insufficient and sufficient

\begin{tabular}{|c|c|c|c|c|c|c|}
\hline $\begin{array}{c}\text { Vit D } \\
\text { (nmol/L) }\end{array}$ & \multicolumn{3}{|c|}{ \% of children in each group } & N & $\%$ \\
\hline & \multicolumn{3}{|c|}{ HbA1c (mmol/mol) } & & \\
\hline & $\leq 60$ & $60-80$ & $81-100$ & $>100$ & & \\
\hline$\leq 25$ & $36.4 \%$ & $36.4 \%$ & $18.2 \%$ & $9.1 \%$ & 22 & $8.40 \%$ \\
\hline $25-50$ & $34.3 \%$ & $37.3 \%$ & $16.7 \%$ & $11.8 \%$ & 102 & $39.10 \%$ \\
\hline$>50$ & $34.3 \%$ & $36.5 \%$ & $16.8 \%$ & $12.4 \%$ & 137 & $52.49 \%$ \\
\hline
\end{tabular}

Table 2: Paired T test

\begin{tabular}{|r|r|r|r|r|}
\hline & N & Mean & SD & SEM \\
\hline $\begin{array}{r}\text { Pre treatment } \\
\text { HbA1C }\end{array}$ & 46 & 70.85 & 18.903 & 2.787 \\
\hline $\begin{array}{r}\text { Post } \\
\text { treatment }\end{array}$ & 46 & 69.85 & 15.948 & 2.351 \\
\hline HbA1C & & & & \\
\hline
\end{tabular}

P Value:0.64

\section{Conclusions}

Low vitamin D concentrations are fairly prevalent in children with T1DM.Glycaemic control does not seem to be influenced by the vitamin D status in our retrospective study. Long term prospective studies are essential. 